ARTICLE OPEN

\title{
Relationship between Azores High and Indian summer
}

\section{monsoon}

\author{
Ramesh Kumar Yadav $\mathbb{1 D}^{1 凶}$
}

A dominant mode of interannual variability of Indian summer monsoon rainfall shows west-east dipole pattern with above normal rainfall towards west and central India and subdued rainfall towards the east and northeast India, and is related to the vigorous Azores High. The vigorous Azores High is accompanied by enhanced subsidence resulting in well-built widespread uppertroposphere convergence. This forms the meridional vorticity dipole consisting of anomalous cyclonic and anti-cyclonic circulation at $30^{\circ} \mathrm{N}$ and $50^{\circ} \mathrm{N}$, respectively, and boosts the Rossby wave source. The cascading down Rossby wave train imposes successive negative, positive and negative Geopotential height (GPH) anomalies over north Mediterranean, northwest and northeast of India, respectively. The negative GPH anomaly at the north Mediterranean increases the Asian jet towards the Caspian Sea, strengthening the monsoon circulation through the 'silk-road' pattern. While, the dipole GPH anomaly north of India shift the Tibetan High westwards, triggering monsoon activity towards the west.

npj Climate and Atmospheric Science (2021)4:26; https://doi.org/10.1038/s41612-021-00180-z

\section{INTRODUCTION}

The Indian summer monsoon (ISM), which is part of the South Asian monsoon system, is one of the largest global phenomena of the general circulation that has its impacts on the global weather and climate, and the life of millions of Indians. It spans a short period from June through September (JJAS) and contributes about $80 \%$ of the annual rainfall in the country. The JJAS seasonal rainfall plays an important role in the water management and the economic planning of the country. It has significant temporal and spatial variations ${ }^{1}$. Its temporal and spatial variation causes large-scale droughts and floods, seriously affecting the agriculture yields and the agrarian economy of the country ${ }^{2}$. The interannual variation of ISM rainfall is not stable in time. In recent decades, it has been observed that the large-scale rainfall band have shifted westward giving more rainfall in the west and central India and below normal rainfall in the east and northeast India, as observed by Yadav ${ }^{3-5}$ and Preethi et al. ${ }^{6}$. Therefore, it becomes very important to study this variation and its teleconnections.

The JJAS seasonal circulation is marked by semi-permanent features of upper-troposphere Tibetan High centred, maximum at the northeast of India and zonally extends from north Africa to northwest Pacific and meridionally extends from the south tip of India to south Caspian Sea (Fig. 1a). It is flanked by an Asian sub-tropical westerly jet-stream (hereafter: Asian jet) to its north (Fig. 1b) and an Indian easterly jet-stream to its south. The strength of the Asian jet in the north is more intense compared to its southern counterpart. The Tibetan High is associated with the strong horizontal divergence (Fg. 1a), which is conducive to the outbreak of convective activity over the Indian subcontinent and the revival of ISM. In the North Atlantic another noticeable semi-permanent feature is the Azores High. It attains its maximum size and strength during JJAS season. It is a large subtropical centre of high atmospheric pressure due to the enormous large-scale subsidence and sinking motion air in the system. In the upper-troposphere, the North Atlantic midlatitude region falls in the path of the circum-global transitory
Rossby wave train moving downstream towards the Eurasian region (Fig. 1c). This wave train was probably first suggested by Kripalani et al. ${ }^{7}$. However the terminology circum-global teleconnection (CGT) wave pattern was suggested by Ding and Wang ${ }^{8,9}$. The strong subsidence in the Azores High generates compensatory widespread horizontal convergence (Fig. 1a) at the upper-troposphere, consequently producing the Rossby wave source in the North Atlantic (Fig. 1c). The North Atlantic is the region of two subtropical westerly jet streams: North American jet in the north and Asian jet in the south (Fig. $1 \mathrm{~b})$. These jets generate positive and negative vorticities towards the north and south of their jet streaks, forming quadrupole types of vorticities (Fig. 1b). So, the North Atlantic is very vibrant and important during summer time as it globally affects the weather and climate circulation patterns. Nevertheless, it remains unclear whether and how the Azores High influences the ISM.

The ISM is a fully coupled land-atmosphere-ocean system. It is linked with the local air-sea interactions and the remote climatic phenomena, such as, El Niño-Southern Oscillation (ENSO), the Indian Ocean Dipole Mode and the Atlantic Niño. The Azores High and Indian rainfall have a similar seasonality of summertime (JJAS) suggestive of a possible linkage between them. Previous studies by Yadav ${ }^{10,11}$ have noticed the influence of Azores High on ISM. These studies state that during nonENSO years, ISM is positively related to the Azores High. The stronger Azores High is associated with the enhanced midtropospheric subsidence forming upper-troposphere (near 250hPa, Fig. 1e) well organized widespread convergence (Fig. 1a). This creates meridional vorticity dipole anomaly compromising anomalous anti-cyclonic and cyclonic circulations at $45^{\circ} \mathrm{N}$ and $30^{\circ} \mathrm{N}$ over the North Atlantic owing to the manifestation of equivalent barotropic and baroclinic structures of the extratropical and tropical regions, respectively, as observed by White $^{12}$ and Wallace ${ }^{13}$. Azores High drives warm oceanic water poleward (known as 'Gulf stream') rising sea surface temperature (SST) over the northwest of North Atlantic. This intensifies

${ }^{1}$ Indian Institute of Tropical Meteorology, Pashan, Pune, India. ${ }^{\circledR}$ email: yadav@tropmet.res.in 

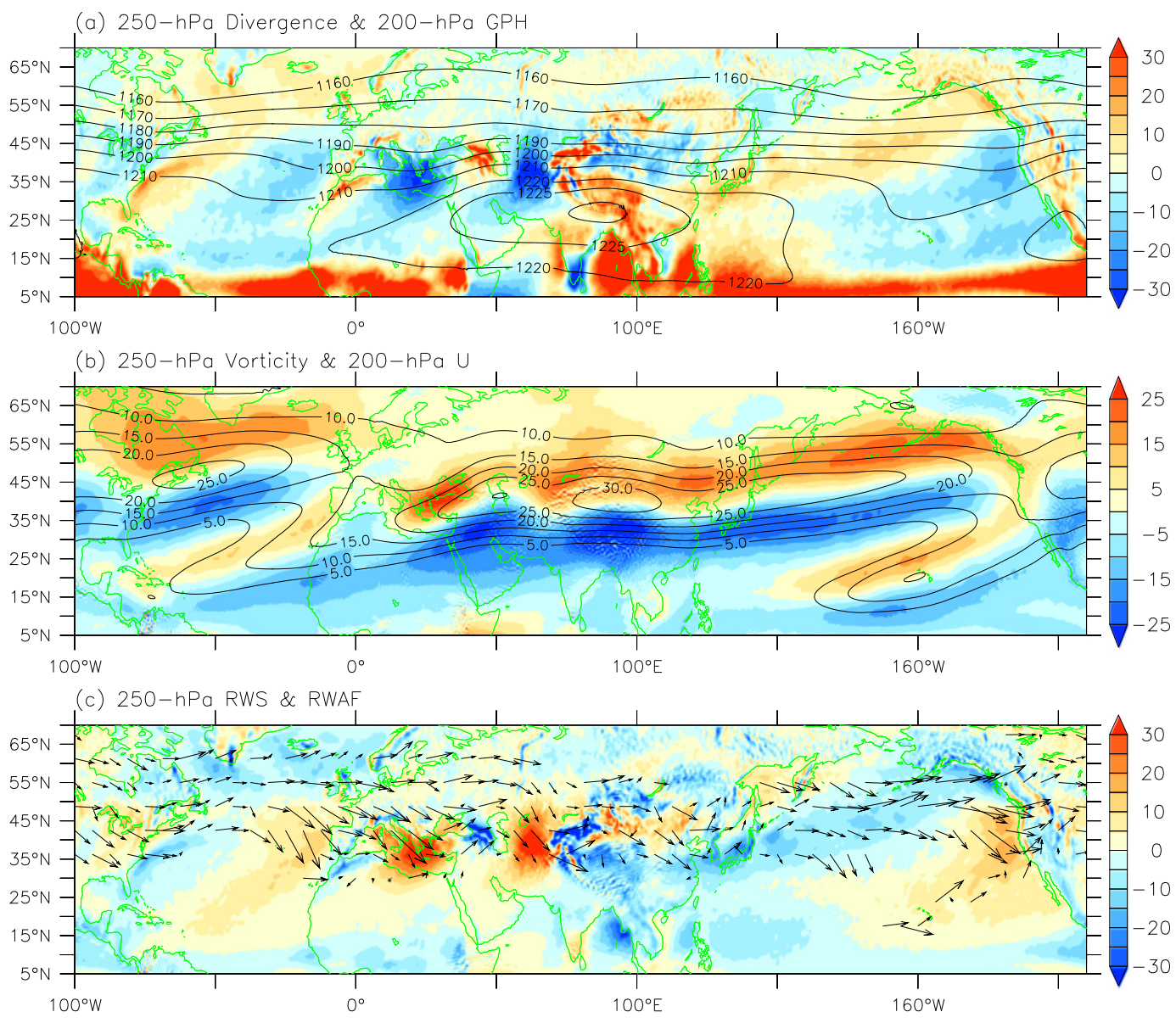

(d) zonal wind 250

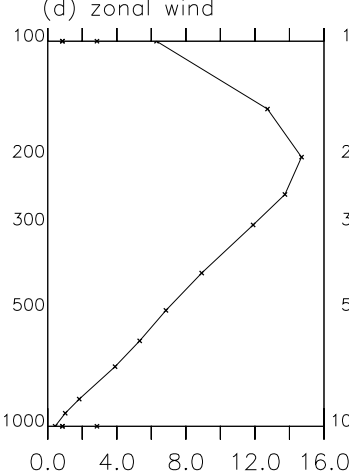

(e) divergence

(f) vorticity

(g) $N N$
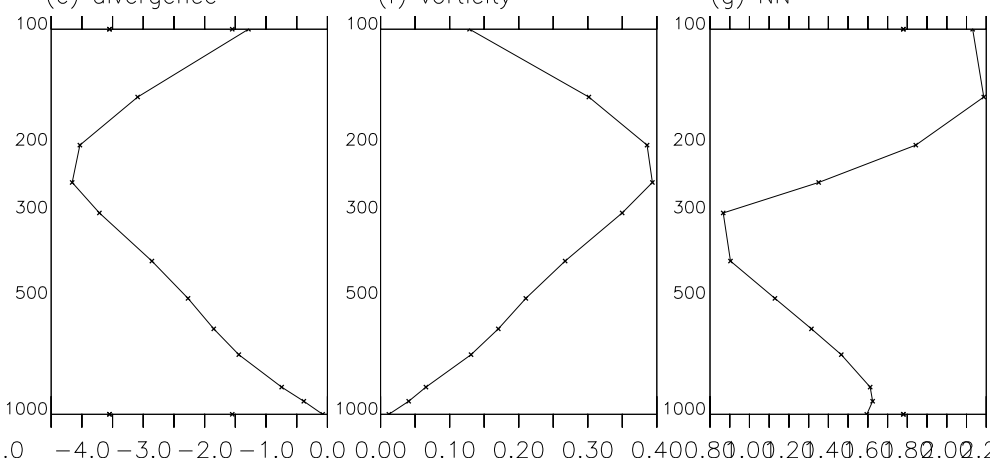

Fig. 1 Climatology. Spatial pattern of seasonal (JJAS) mean climatology (period: 1979-2019) of a 250-hPa Divergence (shaded) and 200-hPa GPH (black contours), b $250-\mathrm{hPa}$ Vorticity (shaded) and $200-\mathrm{hPa}$ Zonal Wind $>5 \mathrm{~ms}^{-1}$ (black contours), c $250-\mathrm{hPa}$ Rossby wave source (shaded) and the horizontal component of Rossby wave flux (black arrows). Vertical profiles of climatological-mean d zonal wind, e divergence, f vorticity and $\mathbf{g}$ Brunt-Väisälä frequency (NN) for the mid-latitude area-averaged region $\left(100^{\circ} \mathrm{W}-110^{\circ} \mathrm{E}, 25^{\circ} \mathrm{N}-65^{\circ} \mathrm{N}\right)$.

and shifts the North American jet to higher latitudes. The jet stream further strengthens the meridional vorticity dipole. The cyclonic circulation intensifies the Asian jet over North Atlantic. A wave activity flux for stationary Rossby waves diverges out of the vorticity dipole toward downstream along the Asian jet stream over the Eurasian region ${ }^{14}$. The jet stream acts as a wave guide and the successive troughs and ridges of the Rossby waves travel along the jet ${ }^{15-17}$ and influence uppertropospheric Tibetan High and hence ISM ${ }^{18,19}$.

The main objective of this study is to investigate the relationship between Azores High and the ISM. This study hypothesized the mechanism by which the Azores High induce anomalous upper-troposphere pressure dipole with positive pressure anomaly at $50^{\circ} \mathrm{N}$ which fall in the path of the preferred
Rossby wave train producing negative and positive pressure anomaly downstream towards north Mediterranean and northwest of India, respectively. While the negative pressure anomaly at $30^{\circ} \mathrm{N}$ in Atlantic escalates the origin of the Asian jet strengthening the 'Silk-Road pattern' affecting the ISM. This pathway provides an important link between Azores High and ISM rainfall variations.

\section{RESULTS}

Association between Azores High and ISM; ISM Teleconnections

To investigate the dominant patterns of ISM variability, Empirical Orthogonal Function (EOF) analysis of the linearly detrended June- 
July-August-September (JJAS) seasonal gridded rainfall over India, excluding north-east India, for the period 1979-2019 have been computed. The north-east India has been excluded from the EOF analysis because of excessive loading and out-of-phase relationship with all India summer monsoon rainfall. The first leading EOF (EOF1), which account for $17.58 \%$ of the variance, show in-phase rainfall anomaly almost all over India except in the east, the states of Bihar and West Bengal, and the rain shadow region of south peninsular India, the state of Karnataka, where out-of-phase anomaly exists. The in-phase maximum loading lies over the Western Ghats followed by west India and central India (Fig. 2a).
The principal component (PC) of EOF1 (PC1) ISM rainfall, is used as a basic function for elucidating its teleconnections. The correlation coefficient between PC1 and gridded JJAS rainfall over India shows significant positive correlation over the Western Ghats, west India and central India and negative correlation over northeast and east India (Fig. 2b). This clearly demonstrates the shift of ISM rainfall westward with excess rainfall over the west and central India and subdued rainfall in the north-east and east India ${ }^{3-6}$.

The correlation between PC1 and gridded 200-hPa geopotential hight (GPH) shows significant positive correlation over North Atlantic, north Europe, north Africa, northwest of India, east Asia
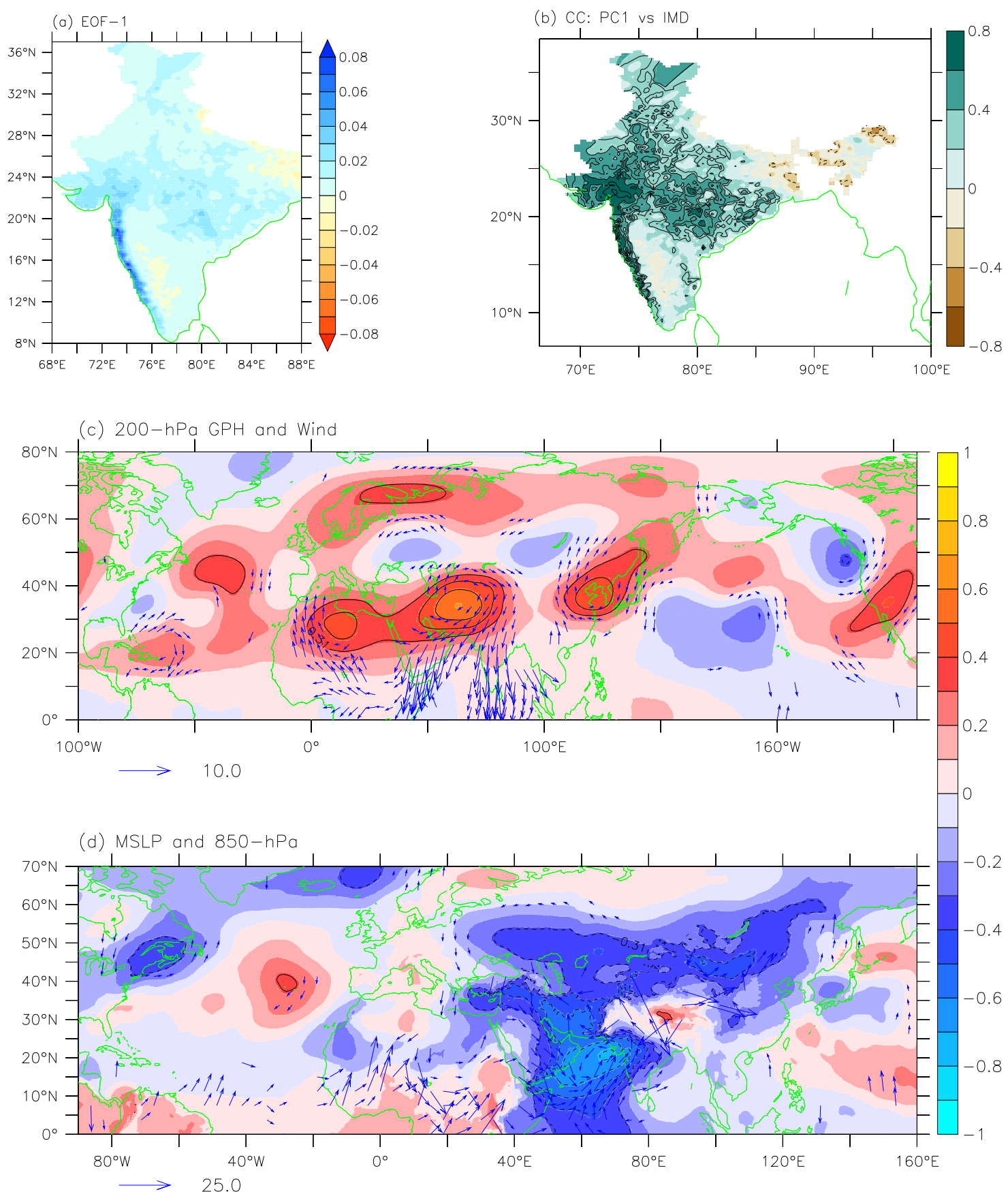

Fig. 2 IMD PC1 correlation. a The first leading EOF of JJAS IMD rainfall anomalies (shaded), correlation of PC1 with b IMD gridded rainfall, c 200-hPa GPH (shaded) and regression of 200-hPa winds onto PC1 (blue vectors), d correlation of PC1 with MSLP (shaded) and regression of $850-\mathrm{hPa}$ winds onto PC1 (blue vectors). Contours show the significance at $95 \%$ confidence level. 
and southwest USA (Fig. 2c), representing CGT pattern. The positive correlation over north Africa display the monsoon-desert relationship. The significant positive correlation over northwest of India is located in the west of the core of Tibetan High, suggesting westward shift of the Tibetan High owing to active monsoon in the west and central India and subdued monsoon activity in the northeast and east India. The significant positive correlation over extra-tropical North Atlantic, above Azores High, ensures the association with the Azores High. A possible link between ISM and Azores High has been investigated by Yadav ${ }^{10,11}$, but it still remains unclear whether and how the Azores High affects ISM. Therefore, it becomes important to re-explore the influence of Azores High on ISM circulation. The 200-hPa wind regression onto PC1 shows westerly anomalies over east of Caspian Sea, suggesting a stronger Asian jet favourable for ISM. The correlation between PC1 and MSLP (Fig. 2d) shows a significant positive correlation over North Atlantic, below the 200-hPa GPH significant positive correlation owing to the mid-latitude equivalent barotropic atmosphere. This positive anomaly refers to the powerful Azores High. The significant negative correlation over Arabian Sea, west and central India illustrate vigorous monsoon in the west and central India ${ }^{3,4}$. The $850-\mathrm{hPa}$ wind patterns are associated with the surface pressure anomalies.

\section{Association between Azores High and ISM; Azores High teleconnections}

The above analysis clearly reveals a relationship between the first dominant mode of ISM and Azores High for the period 1979-2019.
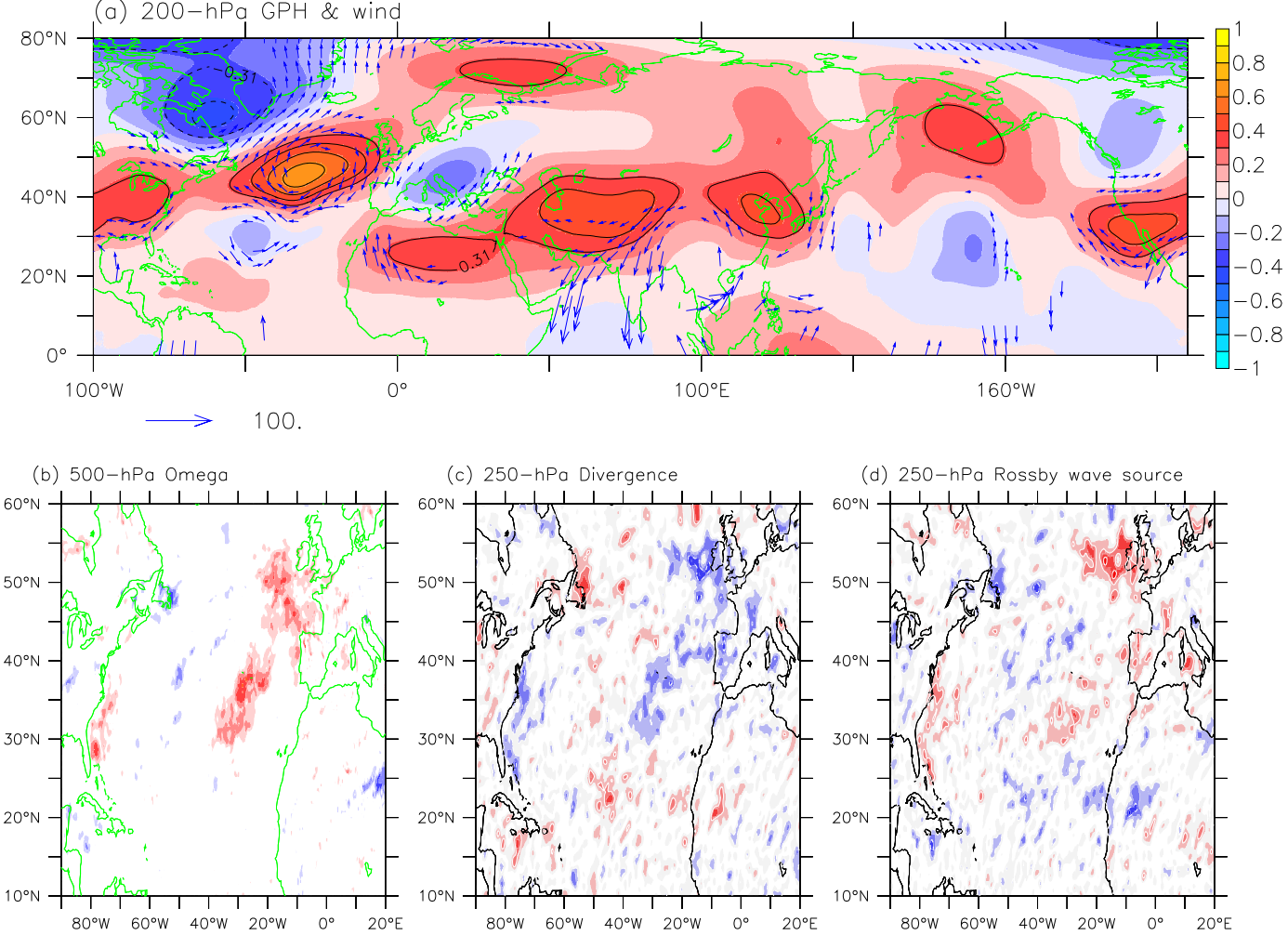

(c) 250-hPo Divergence

(d) 250-hPa Rossby wave source
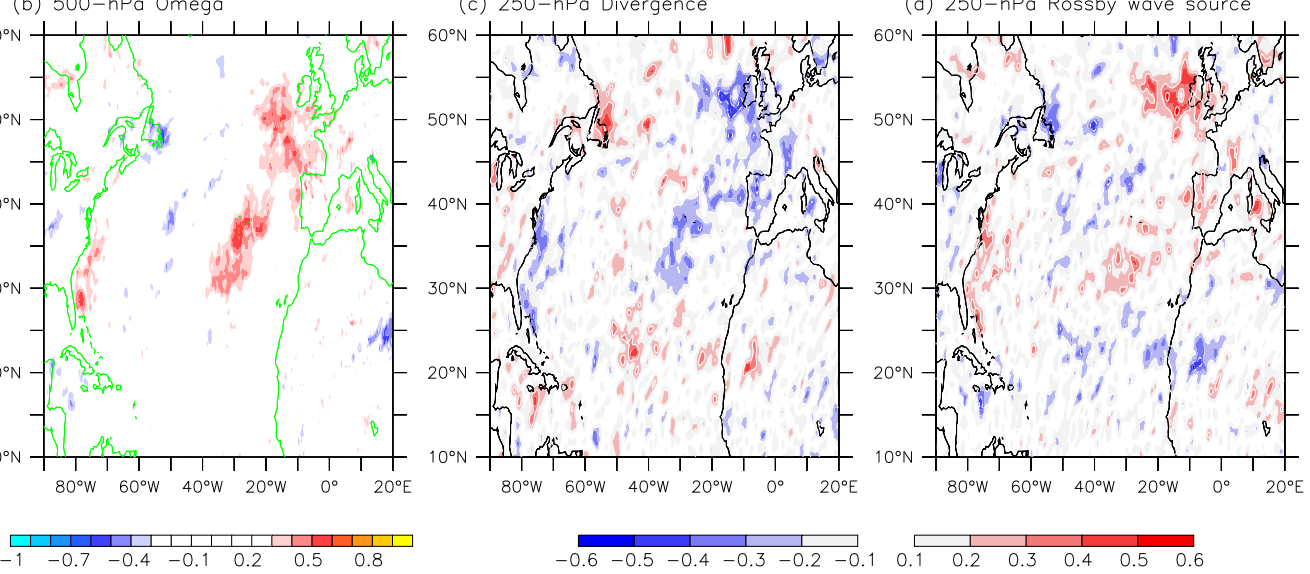

(e) 250-hPa Vorticity \& 300-hPa NN

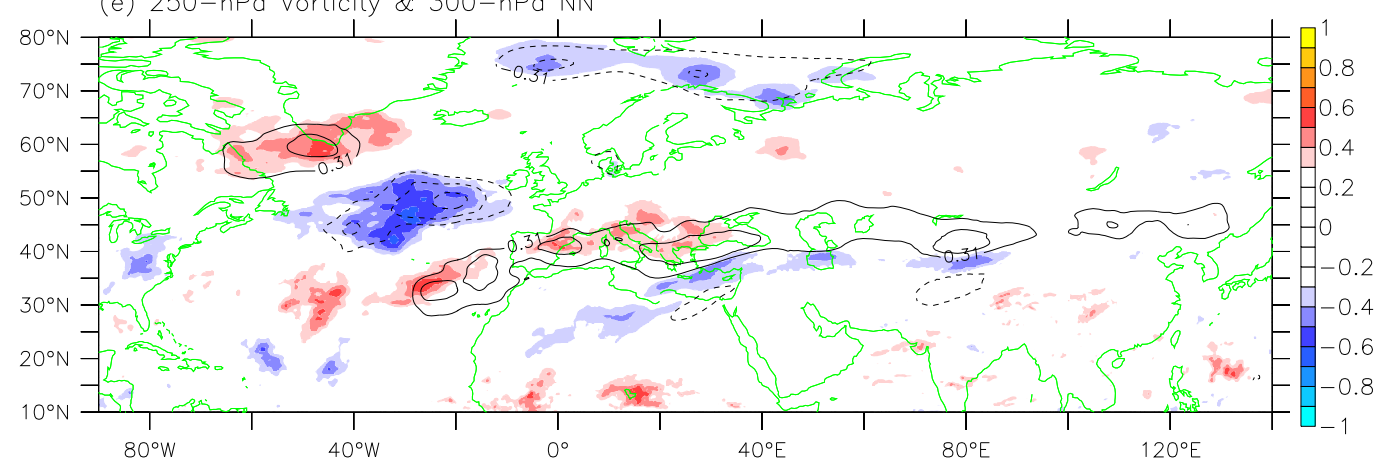

Fig. 3 Azores High correlation. Correlation of AH with a 200-hPa GPH (shaded) and regression of 200-hPa winds onto AH (blue vectors), black contours show the GPH significance at $95 \%$ confidence level. Correlation of AH with b 500-hPa vertical velocity (shaded), c 250 -hPa Divergence, d 250-hPa Rossby wave source, e 250-hPa Vorticity (shaded) and 300-hPa Brunt-Väisälä frequency (NN, black contours). White contours in (c) and (d) shows the significance at $95 \%$ confidence level. 
A time-series has been prepared by averaging MSLP data from the box $\left(320^{\circ} \mathrm{E}-342^{\circ} \mathrm{E}, 30^{\circ} \mathrm{N}-50^{\circ} \mathrm{N}\right)$, which shows the significant positive correlation with the PC1 and is coincident with the position of the Azores High in the North Atlantic, therefore named hereafter as $\mathrm{AH}$. This series is now considered for further exploration of Azores High teleconnections with ISM rainfall. Similar, correlation and regression analysis has been done for $\mathrm{AH}$ (Fig. 3). 200-hPa GPH pattern (Fig. 3a) shows strong CGT patterns as in Fig. 2a. Noticeably, all the six centres of actions (significant positive correlations) in Fig. 2c i.e. located at North Atlantic, north Europe, north Africa, northwest of India, east Asia and southwest USA, are evident in Fig. 3a. The significant negative correlation southwest of Greenland, significant anti-cyclonic and cyclonic circulation anomaly at $50^{\circ} \mathrm{N}$ and $30^{\circ} \mathrm{N}$, forming dipole, in the North Atlantic, respectively, additional patterns are also apparent in Fig. 3a. The successive negative, positive, negative and positive GPH anomalies at the southwest of Greenland, North Atlantic, north Mediterranean and northwest of India manifest a Rossby wave train owing to the Azores High. The significant positive GPH at the northwest of India shifts the core of the Tibetan High westward. Consequently, the large-scale upper-tropospheric divergence induces strong upward motion over the west and central India, facilitating vigorous monsoon convection in these regions. The enhanced convection and latent heating force strong monsoonal circulation in the lower troposphere 20,21 and lead to more water vapour convergence in the boundary layer ${ }^{8}$. This leads to excess rainfall in the west and central India and subdued monsoon activity in the northeast and east India, forming a west-east dipole pattern. The westerly wind anomaly associated with the negative GPH anomalies at $30^{\circ} \mathrm{N}$ in North Atlantic and north Mediterranean increases the Asian jet, favourable for ISM through the 'silk road' pattern.

The $500-\mathrm{hPa}$ vertical velocity correlation with $\mathrm{AH}$ (Fig. 3b) shows a significant positive correlation east of North Atlantic suggesting stronger mid-tropospheric subsidence. The $250-\mathrm{hPa}$ divergence (Fig. 3c) shows a significant negative correlation along the east North Atlantic inferring magnification of uppertroposphere convergence owing to the strong midtropospheric subsidence. The $250-\mathrm{hPa}$ Rossby wave source (Fig. 3d) shows significant positive values at the west of Ireland, southwest Europe and central tropics of the North Atlantic, indicating more generation of Rossby wave source over these regions. The magnified convergence had given rise to the powerful Rossby wave source in this mid-latitude equivalent barotropics atmosphere. Overall, the Azores High is related to mid-tropospheric subsidence, resulting in upper-troposphere convergence, generating Rossby wave source over the east North Atlantic. The $250-\mathrm{hPa}$ vorticity correlation with $\mathrm{AH}$ (Fig. 3e) shows a significant negative correlation at $50^{\circ} \mathrm{N}$ and a significant positive correlation at $30^{\circ} \mathrm{N}$, forming vorticity dipole in the North Atlantic. These negative and positive vorticities are due to the anti-cyclonic and cyclonic circulation found in the Fig. 3a. The significant positive vorticity over north Mediterranean is the consequence of the increased Asian jet. The 300-hPa Brunt-Väisälä frequency (NN), which is measure of the stability of fluid to vertical displacements, shows significant positive correlation, meaning instable atmosphere, along the path of the increased Asian jet. This large zonal scale and small meridional scale reveals the trapped stationary Rossby wave in the form of the atmospheric waveguide ${ }^{16,17,22}$. Therefore, the Asian jet acts as a wave guide, and forms a teleconnection pattern of lowfrequency variability from the North Atlantic and Europe towards central Asia to east Asia, known as the waveguide teleconnection 15,22-26 and 'Silk-Road' pattern' 15,24. Hence, the Azores High modulates the Asian jet, which affects the ISM trough this 'Silk-Road' pattern ${ }^{3,27}$.

\section{Composite analysis and statistical $\boldsymbol{t}$-test}

To understand the circulation features associated with the correlation and regression patterns, composite anomalies and composites of excess and deficient years of Azores High are plotted. Their statistical significance of the difference in means is estimated using the Student's $t$-test for unequal variances ${ }^{28}$. The distinctive features in the composite anomaly plots of 200$\mathrm{hPa} \mathrm{GPH}$ and wind departure from the mean values and composite of 200-hPa zonal wind take into account the physical realism and represent configurations of the variable that are comparable to observations.

The statistical significance of the composite anomaly of excess $(1979,1980,1983,1984,1990,1996,2018)$ and deficient (1985, 1987, 1999, 2003, 2009, 2012, 2014 and 2015) years of Azores High for $200-\mathrm{hPa}$ GPH is presented in Fig. 4. Areas enclosed by the grey dots correspond to $95 \%$ significance level. The significant meridional dipole in the North Atlantic is clearly evident during excess years of the Azores High with a positive anomaly at $50^{\circ} \mathrm{N}$ and negative anomalies at $30^{\circ} \mathrm{N}$ (Fig. 4a). The wind associated with these GPH, constitutes significant anticyclonic and cyclonic circulation anomalies at the extratropical and tropical regions of the North Atlantic, respectively. This dipole pattern is formed as the excess Azores High is associated with intensified mid-tropospheric subsidence inducing magnified upper-troposphere convergence over the North Atlantic. The extratropical and tropical regions develop the anticyclonic and cyclonic circulation anomaly owing to the manifestation of the equivalent barotropic and baroclinic structures of the North Atlantic, respectively, as observed by White ${ }^{12}$ and Wallace ${ }^{13}$. The extratropical anti-cyclonic circulation anomaly increases and shifts the North American jet to higher latitudes. The tropical cyclonic circulation anomaly increases the Asian jet at its entrance at $50^{\circ} \mathrm{W}, 25^{\circ} \mathrm{N}$ (Fig. $4 \mathrm{a}$ ). The successive negative, positive, negative and positive significant GPH anomalies seen at west of Greenland, extratropical North Atlantic, north Mediterranean and east of Caspian Sea, respectively, demonstrate a Rossby wave train during excess years of Azores High. The negative and positive GPH anomalies over the north of Mediterranean and east of Caspian Sea increases the Asian jet over Caspian Sea. The positive and negative GPH anomalies east of Caspian Sea and northeast of India shifts and intensifies the core of Tibetan High westward, thence, shifting the monsoon westward. Moreover, the increased Asian jet (Fig. 4a) does influence the organization of low-frequency variability by producing meridionally trapped zonally elongated disturbance patterns along it through the 'Silk-Road' pattern ${ }^{3,27}$. The jet acts as waveguide and the Rossby wave train over Eurasia propagates along the jet ${ }^{15-17}$.

While, during the deficient years of Azores High the 200-hPa GPH (Fig. 4b) shows significant successive positive, negative and positive anomalies over the southwest of Greenland, extratropical North Atlantic and north Mediterranean respectively, portray a Rossby wave train with opposite GPH signs as observed during excess years of Azores High. The cascading significant positive anomaly observed over the north Mediterranean, associated with the anti-cyclonic circulation anomaly, decreases the Asian jet over the Mediterranean. Notably, the tropical North Atlantic $\left(30^{\circ} \mathrm{N}\right)$ significant GPH anomaly is absent because of the reduced mid-tropospheric subsidence during deficient years of Azores High, in turn has limited the uppertroposphere convergence to extra-tropical North Atlantic. For that reason, the significant negative correlation at tropical North Atlantic $\left(30^{\circ} \mathrm{N}\right)$ is not observed in Fig. 3a. The reduced Asian jet (Fig. 4b) increases the stability of the atmosphere, resulting in reduced ISM. The limited convergence of the North Atlantic weakens the Rossby wave source during deficient years of Azores High. Therefore, the cascading down Rossby wave 

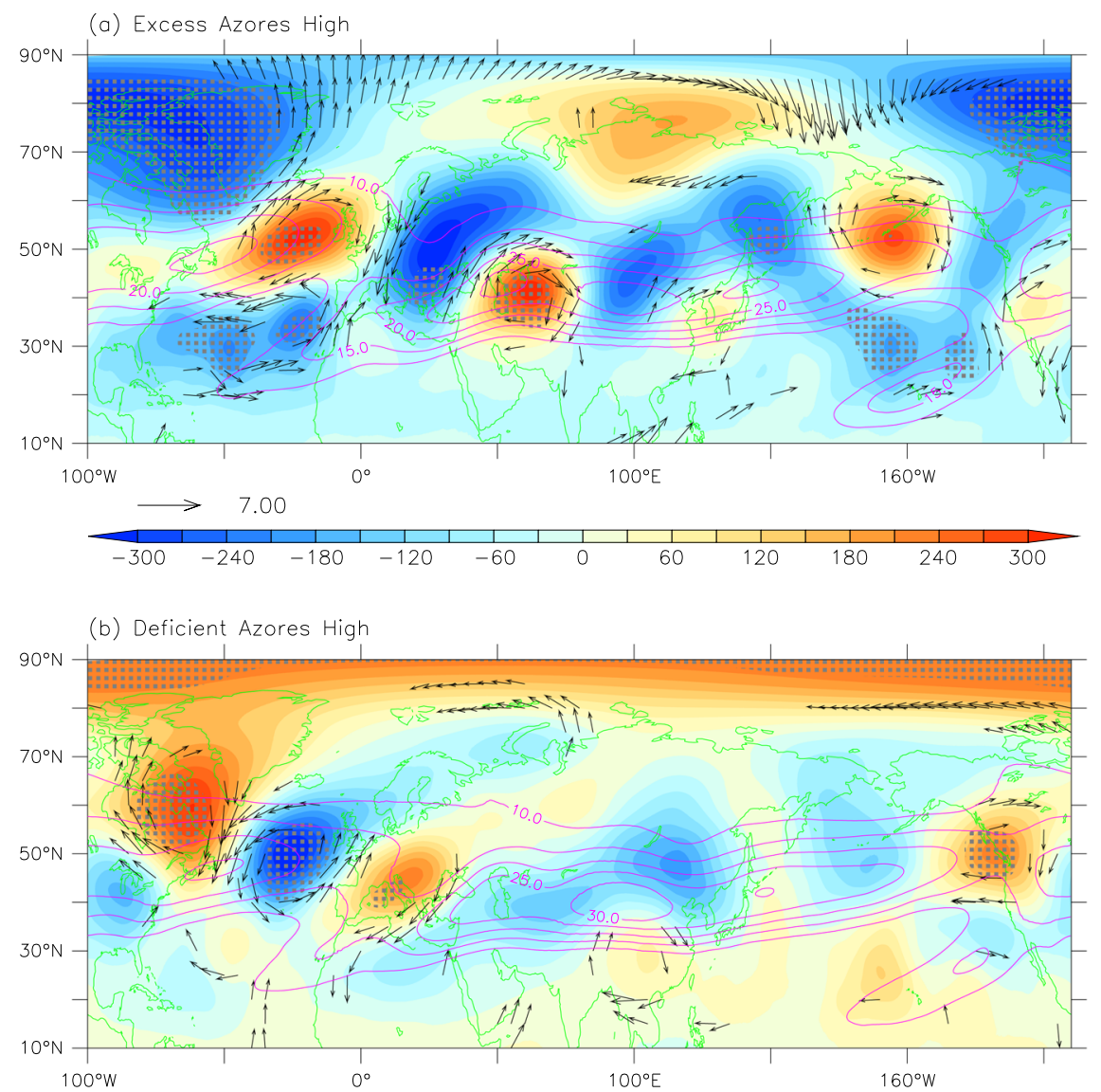

Fig. 4 Composite of Azores High. Composite anomaly of 200-hPa GPH (shaded), 95\% statistical significance of composite of GPH (grey dots) and wind (black arrows) and composite of zonal wind $>5 \mathrm{~ms}^{-1}$ (Cray contours) for a excess and b deficient years of AH, respectively.

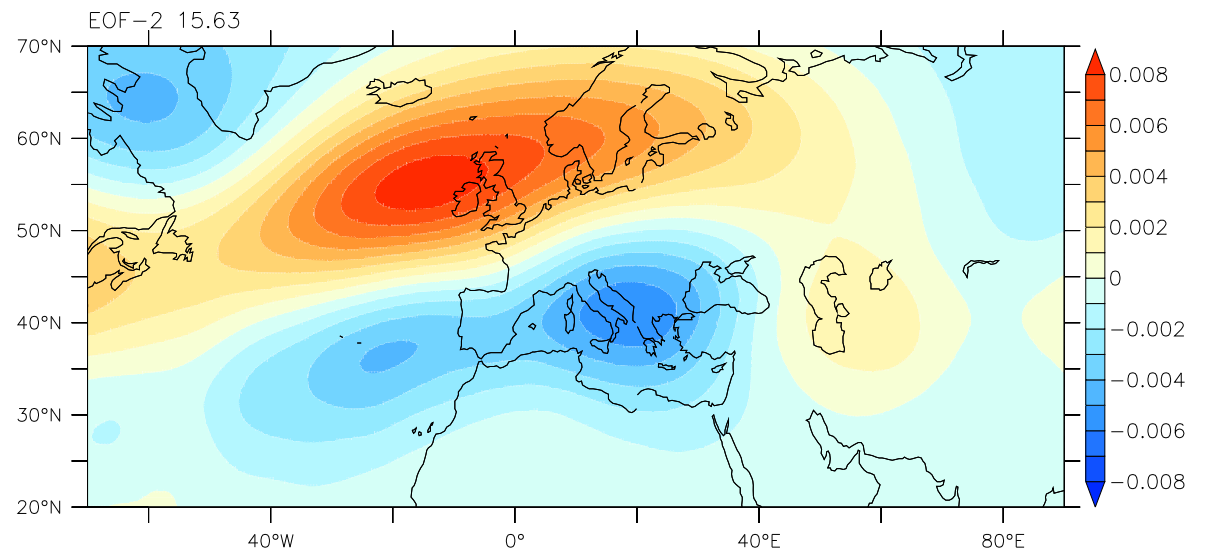

Fig. 5 Atlantic-Eurasian Rossby wave. The second leading EOF of JJAS 200-hPa GPH anomalies (shaded).

erodes towards Asia. However, the weak negative anomaly east of the Caspian Sea and decreased Asian jet mutually lessen the ISM activities over the west and central India.

\section{Relation between North Atlantic-Eurasian wave train and Azores High}

The upper-troposphere is the most important region for the Rossby-wave propagation in the mid-latitudes region. Therefore, 200-hPa GPH EOF for 41-years period from 1979-2019 has been computed over the region $\left(70^{\circ} \mathrm{W}-90^{\circ} \mathrm{E}, 20^{\circ} \mathrm{N}-70^{\circ} \mathrm{N}\right)$ in search of the north Atlantic-Eurasian wave train patterns. The EOF2, which explains $15.6 \%$ variance (Fig. 5) shows in-phase intense anomaly over the extratropical region of North Atlantic (at $18^{\circ} \mathrm{W}, 55^{\circ} \mathrm{N}$ ), weak in-phase anomaly over east of Caspian Sea, intense out-of-phase anomaly observed at north Mediterranean and weak out-of-phase anomalies at the west of Greenland and tropical North Atlantic (at $11^{\circ} \mathrm{W}, 35^{\circ} \mathrm{N}$ ). These GPH anomalies pattern matches with the Azores High correlation with GPH pattern Fig. $3 a$ and significant GPH anomalies in 
Fig. 4a and b. This clearly advocates that the pattern do exists in the North Atlantic-Eurasian region and is the second dominant mode. The correlation between the respective $\mathrm{PC}$ of 200-hPa GPH EOF2 and Azores High series is 0.31 significant at $95 \%$ level, while the correlation of EOF2 PC with ISM is not significant, as the anomaly east of Caspian Sea, which modulates the Tibetan High and hence ISM, is feeble. The east of Caspian Sea positive GPH anomaly intensifies and shifts the Tibetan High westward triggering the monsoon activities towards the west and central India and vice-versa. The extratropical North Atlantic anomaly is the response to the Azores High and is the manifestation of the equivalent barotropic atmosphere. The in-phase GPH anomalies of extratropical North Atlantic and east of Caspian Sea propose the linkages between Azores High and ISM. In addition, the negative GPH anomalies over the tropical North Atlantic and north Mediterranean increase the Asian jet, which consequently boosts the ISM activity and vice-versa.

\section{DISCUSSION}

The ISM is a global phenomenon, as it affects and is also affected by the global weather and climate. The spatial pattern of ISM rainfall in the country is not homogeneous. The maximum rain band remains shifting in different epochs. This changes its global teleconnections. A particular teleconnection has been not always stable with time. This makes the seasonal prediction of ISM more challenging. Therefore, it is required to continuously monitor its global teleconnections for better seasonal prediction and understanding. For that, EOF analysis has been done on the JuneJuly-August-September (JJAS) seasonal variability of India rainfall, for the period 1979-2019, i.e., a total of 41-year boreal summer season (JJAS). The first dominant mode obtained, excluding northeast India, is highly correlated towards the west and central India and anti-correlated to the east and northeast India, suggesting a westward shift of ISM rainfall, creating the westeast dipole pattern of rainfall anomaly. This dominant rainfall pattern is significantly correlated to the Azores High in the North Atlantic.

Analysis suggests the excess Azores High is associated with the intense subsidence producing magnified wide-spread upper-troposphere convergence. The baroclinic and equivalent barotropic atmosphere of the tropical and extra-tropical regions of North Atlantic constitute the cyclonic and anticyclonic circulation anomalies, respectively ${ }^{12,13}$. This circulation forms the meridional vorticity dipole with positive and negative anomalies at $30^{\circ} \mathrm{N}$ and $50^{\circ} \mathrm{N}$, respectively. The positive vorticity (cyclonic circulation) anomaly increases the Asian jet at its entrance (at $50^{\circ} \mathrm{W}, 25^{\circ} \mathrm{N}$ ) in the North Atlantic. In addition, the magnified upper-troposphere convergence at the north Atlantic enhances the Rossby wave source intensifying the circum-global rotating Rossby wave train and the GPH anomalies over the Eurasian region. The cascading down of Eurasian Rossby wave features successive upper-tropospheric negative, positive and negative GPH anomalies over north Mediterranean, northwest of India and northeast of India, respectively. The negative GPH anomalies at the north Mediterranean further intensifies the Asian jet towards the Caspian Sea, while the dipole pressure anomaly north of India shifts the Tibetan High westwards, shifting the intense convection from northeast India to the west and central India and subdued rainfall over the northeast and east India. Thus, forms an anomalous west-east dipole rainfall pattern.

While, the weaker Azores High is associated with moderate subsidence which minimizes the upper-troposphere convergence forming anomalous sole negative $\mathrm{GPH}$ at $50^{\circ} \mathrm{N}$. To note, the upper-troposphere anomalous meridional vorticity dipole structure is missing owing to weaker Azores High. The Eurasian
Rossby wave train imposes a positive GPH anomaly north of the Mediterranean associated with the anti-cyclonic circulation anomaly, which decreases the speed of the Asian jet. The decreased Asian jet increases the stability of the atmosphere, resulting in reduced ISM. The minimized upper-troposphere convergence dwindle the Rossby wave source over North Atlantic. The cascading down of dwindled Rossby wave train from North Atlantic towards Asia forms a feeble negative GPH anomaly east of the Caspian Sea. This weakens the west portion of the Tibetan High consequently reducing rainfall in the west and central India.

The present study is of great importance as it investigates the prospective of the relationship between ISM-Azores High, when the ISM-ENSO relationship has weakened during the study period ${ }^{10,29}$. This study shows how the Azores High modulates the mid-latitude wave pattern over North AtlanticEurasian region, consequently affecting Asian jet and finally ISM rainfall. The influence of mid-latitude wave $\mathrm{s}^{3-5,9}$ and Asian jet $^{27}$ on ISM is well known. But none of the study has shown the relationship of Azores High with ISM through mid-latitude wave and Asian jet. The influence of active Azores High on ISM circulation is more effective as it generates powerful Rossby wave source in the North Atlantic, which energizes the cascading down mid-latitude wave train to Asia, affecting ISM. While, the inactive Azores High influence is feeble as it generates moderate Rossby wave source in the North Atlantic. The cascading down of Rossby wave from North Atlantic wanes towards Asia, limiting the effect on ISM circulation. For this reason, we don't get strong correlation of ISM with Azores High and therefore the relationship not documented earlier. However, the next step could be to examine the extent to which this teleconnection is represented in climate forecast models to aid the seasonal prediction of west and central India summer monsoon rainfall.

\section{METHODS}

Data

The SST, $250-\mathrm{hPa}$ GPH, and $850-$ and $250-\mathrm{hPa}$ zonal and meridional wind for the period 1979-2019 are obtained from the European Centre for Medium-Range Weather Forecasts ERA5 reanalysis dataset at $0.25^{\circ}$ spatial resolution ${ }^{30}$. For rainfall over Indian landmass, the monthly gridded rainfall at $0.25^{\circ} \mathrm{X} 0.25^{\circ}$ resolutions for the period $1979-2019$ is used from the Indian Meteorological Department (IMD) ${ }^{31}$.

\section{Vertical profile}

Vertical profiles of climatological-mean boreal summer (JJAS) zonal wind, divergence, vorticity and Brunt-Väisälä frequency (NN) for the mid-latitude area-averaged region $\left(100^{\circ} \mathrm{W}-110^{\circ} \mathrm{E}, 25^{\circ} \mathrm{N}-65^{\circ} \mathrm{N}\right)$ have been plotted (Fig. 1d-g). These parameters show extrema at different levels in the upper-troposphere. Zonal wind attains its maximum amplitude near 200-hPa level (Fig. 1d). The transient motions and large-scale disturbances in mid-latitude regions have an equivalent barotropic structure in the vertical, with little tilt in wind and pressure field anomalies with height. Therefore, the upper-troposphere wind and $\mathrm{GPH}$ are plotted at 200-hPa level. Similarly, vorticity and divergence extrema are at 250-hPa level (Fig. 1e\&f). The Rossby wave source is calculated from the divergence and vorticity component. Therefore, vorticity, divergence and Rossby wave source are calculated at $250-\mathrm{hPa}$ level. The upper troposphere is the most important region for Rossbywave propagation in the tropical and subtropical regions but, the equivalent barotropic mid-latitude waves are probably best represented using the flow from a slightly lower level ${ }^{32}$. Therefore, the horizontal Rossby wave activity flux is plotted at the 250-hPa level. The minimum in amplitude in the upper-troposphere for Brunt-Väisälä frequency (NN) is located at 300-hPa level (Fig.1g), therefore, to measure the stability of the upper-troposphere to vertical displacements 300-hPa level have been selected. 


\section{EOF, correlation, regression and composite analysis}

EOF analysis is performed on the de-trended JJAS seasonal gridded IMD rainfall data and 200-hPa GPH over North Atlantic-Eurasian region $\left(70^{\circ} \mathrm{W}-90^{\circ} \mathrm{E}, 20^{\circ} \mathrm{N}-70^{\circ} \mathrm{N}\right)$ to study their inter-annual variability of the dominant mode. Other methods used are simultaneous correlation and regression on the de-trended datasets. The excess and deficient years for composite analysis are defined, if the standardized values (i.e., the mean subtracted and divided by the standard deviation) are $>+1$ and $<-1$, respectively (need to define index).

\section{Rossby wave activity flux}

The Rossby wave activity fluxes have been calculated $^{33}$ to show the existence and propagation of the Rossby wave in the mean flow over Eurasian region. The horizontal flux of Rossby wave formulas is as follow:

$\mathrm{W}_{\mathrm{x}}=\frac{\mathrm{p} \cos \phi}{2|\mathrm{U}|}\left(\frac{\mathrm{U}}{\mathrm{a}^{2} \cos ^{2} \phi}\left[\left(\frac{\partial \psi^{\prime}}{\partial \lambda}\right)^{2}-\psi^{\prime} \frac{\partial^{2} \psi^{\prime}}{\partial \lambda^{2}}\right]+\frac{\mathrm{v}}{\mathrm{a}^{2} \cos \phi}\left[\frac{\partial \psi^{\prime}}{\partial \lambda} \frac{\partial \psi^{\prime}}{\partial \phi}-\psi^{\prime} \frac{\partial^{2} \psi^{\prime}}{\partial \lambda \partial \phi}\right]\right)$

$W_{y}=\frac{p \cos \phi}{2|U|}\left(\frac{U}{a^{2} \cos \phi}\left[\frac{\partial \psi^{\prime}}{\partial \lambda} \frac{\partial \psi^{\prime}}{\partial \phi}-\psi^{\prime} \frac{\partial^{2} \psi^{\prime}}{\partial \partial \partial \phi}\right]+\frac{v}{a^{2}}\left[\left(\frac{\partial \psi^{\prime}}{\partial \phi}\right)^{2}-\psi^{\prime} \frac{\partial^{2} \psi^{\prime}}{\partial \phi^{2}}\right]\right)$

here $\mathbf{W} x, y$ are the wave flux in the horizontal $\mathrm{x}$ and $\mathrm{y}$ direction, $a$ is the earth's radius, $(\phi, \lambda)$ are latitude and longitude, respectively, Geostrophic stream function is defined as $\psi=\phi / f$, where $\phi$ is geopotential and $\mathrm{f}(=2$ $\Omega \sin \phi)$ the Coriolis parameter with the earth's rotation rate $\Omega, \psi^{\prime}$ is perturbation streamfunction, $\mathrm{U}$ is zonal wind, $\mathrm{V}$ is meridional wind, $|\mathrm{U}|$ is wind magnitude, and $\mathrm{p}$ is pressure normalized by $1000-\mathrm{hPa}(=$ pressure/ $1000-\mathrm{hPa}$ ). In theory, the flux $\mathbf{W}$ is independent of wave phase and parallel to the local group velocity of planetary waves. The flux tends to diverge out of forcing regions. The details of the individual terms of $\mathbf{W}$ are explained by Takaya and Nakamura ${ }^{33}$.

\section{Rossby wave source}

The divergence and vorticity are calculated from the zonal and meridional wind component. The Rossby wave source is computed following Sardeshmukh and Hoskins ${ }^{34}$

$\mathrm{S}=-\nabla \cdot\left(\mathrm{v}_{\mathrm{x}} \xi\right)$

where $\xi \equiv \zeta+f$ is the absolute vorticity, $\zeta$ is relative vorticity while $\mathbf{v}_{\mathrm{x}}$ is the divergent wind vector calculated from the velocity potential field. Note that the wave source $S$ is computed by means of seasonal mean fields so that it excludes a contribution from subseasonal and submonthly perturbations.

\section{DATA AVAILABILITY}

The IMD and reanalysis gridded data set are downloaded from their respective websites: https://www.imdpune.gov.in/Clim_Pred_LRF_New/Grided_Data_Download. html and https://cds.climate.copernicus.eu/cdsapp\#!/dataset/reanalysis-era5-singlelevels-monthly-means?tab=overview, respectively.

Received: 6 November 2020; Accepted: 25 February 2021; Published online: 26 April 2021

\section{REFERENCES}

1. Goswami, B. N. South Asian summer monsoon. Intraseasonal Variability of the Atmosphere-Ocean Climate System (eds. Lau, W. K. M. \& Waliser, D. E.) 19-62 (Springer, 2005).

2. Saha, K. R., Mooley, D. A. \& Saha, S. The Indian monsoon and its economic impact. Geo. J. 3, 171-178 (1979).

3. Yadav, R. K. On the relationship between Iran surface temperature and northwest India summer monsoon rainfall. Int. J. Climatol. 36, 4425-4438 (2016).

4. Yadav, R. K. Mid-latitude Rossby wave modulation of the Indian summer monsoon. Q. J. R. Meteorol. Soc. 143, 2260-2271 (2017a).

5. Yadav, R. K. On the relationship between east equatorial Atlantic SST and ISM through Eurasian wave. Clim. Dyn. 48, 281-295 (2017b).

6. Preethi, B., Mujumdar, M., Kripalani, R. H., Prabhu, A. \& Krishnan, R. Recent trends and tele-connections among South and East Asian Monsoons in a warming environment. Clim. Dyn. 48, 2489-2505 (2017).
7. Kripalani, R. H., Kulkarni, A. \& Singh, S. V. Association of the ISM with NH midlatitude circulation. Int. J. Climatol. 17, 1055-1067 (1997).

8. Ding, Q. \& Wang, B. Circumglobal Teleconnection in the Northern Hemisphere Summer. J. Clim. 18, 3483-3505 (2005).

9. Ding, Q. \& Wang, B. Intraseasonal teleconnection between the summer Eurasian wave train and the Indian Monsoon. J. Clim. 20, 3751-3767 (2007).

10. Yadav, R. K. Changes in the large-scale features associated with the Indian summer monsoon in the recent decades. Int. J. Climatol. 29, 117-133 (2009a).

11. Yadav, R. K. Role of equatorial central Pacific and northwest of North Atlantic 2metre surface temperatures in modulating Indian summer monsoon variability. Clim. Dyn. 32, 549-563 (2009b).

12. White, G. H. An observational study of the Northern Hemisphere extratropical summertime general circulation. J. Atmos. Sci. 39, 24-40 (1982).

13. Wallace, J. M. in Largescale Dynamical Processes In The Atmosphere. (eds. Hoskins, B. J. \& Pearce, P. R.) 27-53 (Academic Press, 1983).

14. Miyasaka, T. \& Nakamura, H. Structure and formation mechanisms of the Northern Hemisphere summertime subtropical highs. J. Clim. 18, 5046-5065 (2005).

15. Lu, R.-Y., Oh, J.-H. \& Kim, B.-J. A teleconnection patternin upper-level meridional wind over the North African and Eurasian continent in summer. Tellus 54A, 44-55 (2002).

16. Hoskins, B. J. \& Ambrizzi, T. Rossby-wave propagation on a realistic longitudinally varying flow. J. Atmos. Sci. 50, 1661-1671 (1993).

17. Ambrizzi, T., Hoskins, B. J. \& Hsu, H. H. Rossby-wave propagation and teleconnection patterns in the austral winter. J. Atmos. Sci. 52, 3661-3672 (1995).

18. Ramaswamy, C. Breaks in the Indian summer monsoon as a phenomenon of interaction between the easterly and the sub-tropical westerly jet streams. Tellus 14, 337-349 (1962).

19. Raman, C. R. V. \& Rao, Y. P. Blocking highs over Asia and monsoon droughts over India. Nature 289, 271-273 (1981).

20. Wang, B. \& Xie, X. S. Low-frequency equatorial waves in vertically sheared zonal flow. 1. Stable waves. J. Atmos. Sci. 53, 449-467 (1996).

21. Xie, X. \& Wang, B. Low-frequency equatorial waves in vertically sheared zonal flow. Part II: Unstable waves. J. Atmos. Sci. 53, 3589-3605 (1996).

22. Branstator, G. Circumglobal teleconnections, the jet stream waveguide, and the North Atlantic oscillation. J. Clim. 15, 1893-1910 (2002).

23. Hsu, H. H. \& Lin, S. H. Global teleconnections in the $250-M b$ streamfunction field during the northern-hemisphere winter. Monthly Weather Rev. 120, 1169-1190 (1992).

24. Enomoto, T., Hoskin, B. J. \& Matsuda, Y. The formation mechanism of the Bonin high in August. Q. J. R. Meteorol. Soc. 129, 157-178 (2003).

25. Hu, K., Huang, G., Wu, R. \& Wang, L. Structure and dynamics of a wave train along the wintertime Asian jet and its impact on East Asian climate. Clim. Dyn. 51, 4123-4137 (2018).

26. Teng, H. \& Branstator, G. Amplification of waveguide teleconnections in the Boreal summer. Curr. Clim. Change Rep. 5, 421-432 (2019).

27. Yadav, R. K., Srinivas, G. \& Chowdary, J. S. Atlantic Niño modulation of the Indian summer monsoon through Asian jet. npj Clim. Atmos. Sci. 1, 23 (2018).

28. Press, W. H., Flannery, B. P., Teukolsky, S. A. \& Vetterling, W. T. Numerical Recipes in The Art of Scientific Computing. 2nd edn. 611-612 (Cambridge University Press, 1992).

29. Krishna Kumar, K., Rajagopalan, B. \& Cane, M. A. On the weakening relationship between the Indian monsoon and ENSO. Science 284, 2156-2159 (1999).

30. Hersbach, $H$. et al. The ERA5 global reanalysis. Q. J. R. Meteorol. Soc. 146, 1999-2049 (2020).

31. Pai, D. S. et al. Analysis of the daily rainfall events over India using a new long period $(1901-2010)$ high resolution $\left(0.25^{\circ} \times 0.25^{\circ}\right)$ gridded rainfall dataset. Clim. Dyn. 45, 755-776 (2015).

32. Held, I. M., Panetta, R. L. \& Pierrehumbert, R. T. Stationary external Rossby waves in vertical shear. J. Atmos. Sci. 42, 865-883 (1985).

33. Takaya, K. \& Nakamura, H. A formulation of a phase-independent wave-activity flux for stationary and migratory quasigeostrophic eddies on a zonally varying basic flow. J. Atmos. Sci. 58, 608-627 (2001).

34. Sardeshmukh, P. D. \& Hoskins, B. J. The generation of global rotational flow by steady idealized tropical divergence. J. Atmos. Sci. 45, 1228-1251 (1988).

\section{ACKNOWLEDGEMENTS}

The author appreciates the editors and the anonymous reviewers for their encouraging remarks and comments that helped in the improvement of the manuscript. The data have been taken from Web sites and all data sources are duly 
acknowledged. Computational and graphical analyses required for this study have been completed with the free software NCL and Ferret.

\section{AUTHOR CONTRIBUTIONS}

R.K.Y. designed and conceived the study, conducted the analysis, interpreted the results, and wrote the manuscript.

\section{COMPETING INTERESTS}

The author declares no competing interests.

\section{ADDITIONAL INFORMATION}

Correspondence and requests for materials should be addressed to R.K.Y.

Reprints and permission information is available at http://www.nature.com/reprints
Publisher's note Springer Nature remains neutral with regard to jurisdictional claims in published maps and institutional affiliations. cc) Open Access This article is licensed under a Creative Commons adaptation, distribution and reproduction in any medium or format, as long as you give appropriate credit to the original author(s) and the source, provide a link to the Creative Commons license, and indicate if changes were made. The images or other third party material in this article are included in the article's Creative Commons license, unless indicated otherwise in a credit line to the material. If material is not included in the article's Creative Commons license and your intended use is not permitted by statutory regulation or exceeds the permitted use, you will need to obtain permission directly from the copyright holder. To view a copy of this license, visit http://creativecommons. org/licenses/by/4.0/.

(c) The Author(s) 2021 